\title{
Keeping Conversation Rolling by Iraqi EFL University Learners
}

\author{
Muayad Mingher Al-Shemmery ${ }^{1}$, Hisham Adnan AlMumar ${ }^{2} \&$ Dheyaa Al-Fatlawi ${ }^{3}$ \\ ${ }^{1}$ Department of Architecture, College of Engineering, University of Babylon, Babylon, Iraq \\ ${ }^{2}$ Department of Regional Planning, College of Physical Planning, University of Kufa, An Najaf, Iraq \\ ${ }^{3}$ Department of English, College of Arts, University of Al-Qadisiyah, Al-Qadisiyah, Iraq \\ Correspondence: Hisham Adnan AlMumar, Department of Regional Planning, College of Physical Planning, \\ University of Kufa, An Najaf, Iraq. E-mail: hushama.jasim@uokufa.edu.iq
}

$\begin{aligned} & \text { Received: April 13, } 2019 \\ & \text { Accepted: May 11, } 2019 \quad \text { Online Published: May 23, } 2019 \\ & \text { doi:10.5539/ells.v9n2p84 }\end{aligned} \quad$ URL: https://doi.org/10.5539/ells.v9n2p84

\begin{abstract}
The present study sheds some light on the conversation as an optimal form of communication. Also, it tries to illustrate Iraqi EFL learners' aptitude for producing conversation and specifying the errors types committed by them in its progression. To accomplish these purposes, it is hypothesized that the learners may face formidable problems in sharing their experiences with each other and are unable to keep a conversation going. In the face of such problems, a sample of (50) learners is selected to a diagnostic test administration. The subjects are at the Fourth year, Department of English, College of Education for Humanities, University of Babylon. Data analysis has proved that the leaners encounter more difficulty on the production level than the recognition one. This manifestation is manifested itself in the number of the learners' correct responses as compared with their incorrect ones on both levels.
\end{abstract}

Keywords: conversation, maxim, floor, backchannels, reliability

\section{Introduction}

Individuals generally need to interact with each other in real-life situations, and that process of interaction often takes the form of conversation. It is a universal human activity which may uncover something important and necessary for the human experience. Everyday talk occurs everywhere, in all communities and includes every single social class of people. Its goal is to connect people with each other and the world we are living in. The problem the current study treats is that the learners of Iraqi EFL may not be able to converse in a conversation. In other words, they may communicate their wants and needs ineffectively. Also, it is hard for them to sustain conversations in a situation where they are.

\section{Conversation in English}

\subsection{What Is Conversation}

The term conversation is defined by Gabor $(1983$, p. 13) as the primary way to express our feelings, sentiments, thoughts, goals, and opinions to others we come to encounter with. It is also the primary means to start and establish new friends as well as relationships. Conversation, according to McArthur (1992), is "the most basic and widespread linguistic means of conducting human affairs". It is naturally occurring in the spoken form of language used between speakers and listeners in a variety of social contexts. Hence, the conversation is any interaction or spoken exchange between two or more persons (Pridham, 2001, pp. 1-2).

For Isaacs (1993), the root of conversation can mean "to turn together". Conversation, then, is people talking together, engaging in reflection and deliberation. This reflection and deliberation enable participants to consciously and unconsciously express different trends, finding some with which they agree, and others that they disagree (Jenlink \& Banathy, 2008, p. 5).

Based on Geis's (1995, p. 184) experience, the conversation is often governed by sets of turns in which parties seem to be engaged in doing particular something and the utterances that consist the turn seem to come in pairs. In Cutting's (2002, p. 23) view, conversation is the tool engaged communicating social relations and personal viewpoints, showing solidarity and keeping up the social union. Speakers who contribute to a conversation building up shared view, sharing a typical perspective and negotiating role-relationships are talking with an interactive nature or reason. Actually, most talk has a blend of a mixture of two functions: there seems to be a 
continuum from simply transactional to the absolutely interactional.

Among different speech situations, conversation is the most common form of discourse, accounting for more than $90 \%$ of all spoken form of language. It is the manner by which individuals mingle, create and continue their relations with one another and is considered as the essence of spoken discourse synonymous with spoken interaction in general (Cheng, 2003, p. 12). In order to communicate effectively, conversation is one of the most widespread uses of human language. It is the way in which people socialize, develop and maintain their relations with each other. When individuals have a conversation, they involve in a form of linguistic communication, but there is "much more going on in a conversation than just the use of a linguistic code. Much that is important in conversation is carried by things other than language, including eye gaze, and body postures, silences and the real-world context in which the talk is produced" (Liddicoat, 2007, p. 1).

Practically, conversation, however, is so much bigger than just word of mouth recommendations for buying stuff. It is about life, love, laughter, sadness, frustration, nothing, everything, all of the above, and none of the above. It's about how "just doing it" changed my life as much as it's (Jaffe, 2007, p. 4). In general, the conversation is a give and take of talk; it is the act of idea sharing; it is the readiness to exchange information on all subjects, personal and universal, and in turn to listen to feelings of others regarding the idea advanced (Conklin, 2009, p. 12).

It seems that there is no difference between a definition and another as they all almost show similar interpretations.

\subsection{Features of Conversation}

\subsubsection{Conversational Structure}

As one of the conversationalists, Cook $(1989$, p. 51) notes that conversation is broadly used, in a non-technical sense, and people are able to distinguish it from other kinds of talk. They mean, broadly speaking, that the talk is somehow less formal. Discourse analysts are sometimes not clear enough about what they mean by "conversation", and some seem to use this term to describe any kind of spoken form of interaction. He (ibid) limits the structure of a conversation to the following sort of manner:

a) It is not mainly necessary for a practical task.

b) Any of not equal power of participants is partly suspended.

c) The participants are small in number.

d) Turns are really short.

e) Talk is mainly for the participants, but not for people from the outside.

In this context, Yule (1996, pp. 72-75) specifies clearly different structures existed in a conversation:

a. Floor

According to him, floor can be defined as the current privilege to talk in a conversation. In other words, it is the right of one member to speak in preference to other members in a discussion, i.e., every single turn that the speaker has to speak is called floor.

b. Turn-taking

It is the change of the speaker during a conversation or the way that each participant takes a turn in conversation. As it is a form of social activity, turn-taking works in accordance with a set of conventions for getting turns, keeping them, or leaving them.

c. Transition relevance place

It is a point in a conversation where a shift of turn is acceptable in a particular situation. For the most part, speakers can wait until one of them indicates that $\mathrm{s} /$ he has finished, usually by making a sign for a completion point such as asking inquiring or pausing when the structure is completed like a phrase or a sentence (ibid).

d. Overlap

It is a condition where more than one speaker talking at the same time in a conversation. Generally, only one participant talks at a time and there tends to be avoidance of silence between talking turns. If more than one person intends to speak simultaneously, one of them usually stops (ibid, p. 73).

e. Pause

It is the silence between turns. If the normal belief is that points completed are signaled by the end of a sentence 
and a pause, then one way to maintain the turn is to keep away those markers happen together.

\section{f. Attributable silence}

It is the absence of speech when a participant is given the right to speak in a conversation. In any culture, if the pause is meant to carry some meanings, analysts name it "attributable silence" (ibid, p. 74).

\section{g. Backchannels}

It is an indication that the listener pays attention to the speaker. There are many different cases to do that, such as head nods, smiles, and other expressions of the face, as well as gestures but the most happening vocal indicators, are called backchannel signals, or simply backchannels.

This term expresses the use of words like (yes, really?) or sounds (hmm, oh) by the listener while somebody is engaging in a speech (ibid, p. 75).

\subsubsection{Conversational Maxims}

Cook (1989, p. 29) observes that conversation should follow the rules of polite behavior because a conversation is a social interaction, so it depends on social conventions. Any Failure to stick to these rules will lead to discontinuing the conversation. The idea that conversation continues according to rules known and applied by most of the human beings, was first proposed by the philosopher Grice (1975), who presented what he described as the cooperative principle. Grice's principle (as cited in Radford et al., 2009, p. 396) implies decisions in four areas:

a) Maxim of Quality: try to make your contribution one that is true;

i. do not say what you believe to be false;

ii. do not say that for which you lack adequate evidence.

b) Maxim of Quantity:

i. make your contribution as informative as is required for the current purposes of the exchange;

ii. do not make your contribution more informative than is required.

c) Maxim of Relation: make your contribution relevant

d) Maxim of Manner: be perspicuous, and specifically

i. avoid obscurity;

ii. avoid ambiguity;

iii. be brief;

iv. be orderly.

The point of the Co-operative Principle and the maxims is not to inform others how to behave in a certain situation, but the point is that speakers are allowed not to follow the maxims in order to convey something over and above the literal meaning of the utterance (ibid, p. 397).

\subsection{Kinds of Conversation}

According to their purpose, the linguist Halliday (1973) tries to separate conversations as follows:

- Some conversations fulfill a practical need, either to serve our relations with other people or to regulate their behavior.

- In many times, people can learn from conversations either they can tell about the world we live in or learn how to express ourselves and our personalities.

- Sometimes, conversations and imagination are used to amuse people, represent new plans and ideas or to create imaginary worlds (Pridham, 2001, p. 5).

Among those who classify conversation into types is Turnbull. He (2003, p. 2) announces other types of conversation, in particular, a conversation which involves more than two participants and conversation between people from different cultures. Also, there is a conversation without visual interaction (e.g., conversation on the telephone), and there is a conversation with varying degrees of formality (e.g., formal situations such as the classroom, the courtroom, and the therapy session).

As for the situations in which they occur, conversations can be classified as follows:

- face-to-face conversations: they can be private, such as home talk between the family members, or in public 
and ritualized exchanges such as talk in the classroom or questioning in the Parliament House;

- non-face-to-face conversations, such as telephone exchanges;

- broadcast materials, such as a TV chat show or live radio phone-in (Pridham, 2001, p. 2).

According to their major subject content, many conversations can be divided into the following:

- Subjective ideas: they often provide to extend awareness and understanding.

- Objective facts: they can serve to strengthen widely held viewpoints.

- Other people: they might either be supportive, competitive or critical. This subject may include gossip.

- Oneself: they sometimes suggest or show attention, seeking behavior or may provide information about somebody to take part in the conversation.

From a practical viewpoint, a few conversations can exclusively be classified into one category. Nonetheless, the degree of distribution of any given exchange between categories may offer useful psychological understanding into the mind of the interlocutors. That is why the majority of exchanges are not easy to categorize (https://en.wikipeddia.org./wiki/conversation).

\subsection{How to Start a Conversation}

Gabor (1983, p. 35) suggests five steps to start a conversation. These do not always occur in this order:

1) Risk vs. rejection: being the first person to say "hello", most hesitant and shy people do not commence conversation because they are fearful to be rejected. By commencing a conversation, their fear of rejection will be lessened. It also gives the opportunity to direct the conversation and gives the impression that the speaker is confident, friendly and open.

2) Ritual questions: asking easy questions about the environment, the situation or the other person. The easiest way to initiate an exchange with someone you do not know is to notice something interesting about him and offer a compliment in a sincere and friendly manner (ibid, p. 39).

3) Active listening: listening carefully helps people with what to say next and encourages them to speak. It proves that their attention is concentrated on the conversation (ibid, p. 49).

4) Seek information: asking good follow-up questions based on free information to allow for clarification and elaboration. Occasionally, free information may comprise a general impression (ibid, p. 55).

5) Self-disclosure: revealing a lot of his/her free information in the course of asking questions may be interesting to the speaker personally. It is a way to let others get to know the speaker on his/her own terms, i.e., the speaker's friendly relation (ibid, p. 58).

Keller and Warner (1990, p. 5) view that the beginning of a conversation is usually the most difficult part for most people. If the participants start in a natural and friendly way, they most likely have a positive meeting. If they start "on the wrong foot", they will be misunderstood. Therefore, they use opening gambits not only to start a conversation but also to introduce ideas during a conversation. So, the speaker may wish to get someone's attention by saying, Excuse me, please, or to introduce a surprising piece of news with, You may not believe this, but...... or he may want to add a small piece of information with, By the way. They (ibid, p. 60) add that the gambits are used to agreement or disagreement or to show surprise, disbelieve, or polite interest. For them, the most useful gambits are, Sorry I don't follow you to get people to repeat what they said, and really? To get them to develop what they said.

For a successful conversation, Hayashi $(2011$, p. 8 ) establishes a base for starting every conversation:

1) Self-awareness: to know what you feel in the moment enable you to create different outcomes in conversations with others.

2) Self-regulation: to determine what to do with emotions is to be aggressive instead of being active to an emotion. You are deliberately changing your emotional state in order that you do not take control of a conversation in a way you might regret later.

3) Motivation: to know what makes you excited and play to your own feelings when you make decisions; use your favorite skills and abilities so you enjoy your work.

4) Empathy: to be able to identify what someone else feels in the moment and work that into the exchange to create a friendly relationship.

5) Social skills: to be able to work with groups, to arrange the group members around common goals in order to 
create a forward improvement.

\subsection{How to Keep a Conversation Going}

Continuing in a conversation is easy if someone knows the most important factors involved. Good body language, showing curiosity and interest, and being kind and enthusiastic are necessary and important. Gabor (1983, p. 75) offers six decisive factors to make conversations easily and naturally continue.

1) One way to keep a conversation going is to focus on the situation you are in. And the best way to do this is by identifying yourself in your immediate environment so as to talk with other persons simply by concentrating on the different aspects of the environment and the nearby places.

2) During the talk, try to discover about the "big" social occasions in the life of other persons to make the talk go on longer. The big occasions in the individual's life "hot buttons" are spots that are of eager interest to create a feeling of excitement in individuals you converse with as well as in yourself.

3) Balance the two-way information exchange. The participants have to balance the exchange of information between listening and talking. It is like a game "take and give" in order for the conversation to be meaningful.

4) Choose good topics that are essential to you. In this case, the other participant will get an impression and opinion of your character and they also provide huge material of conversation to deliver an effective speech.

5) Move on to another topic using free information. Bring the conversation back by mentioning some information known previously, or offering some pieces of new information of your own to your conversation partner.

6) Find out what other person is interested in. Sharing common interest and experience enable you to build a connection between you and the interlocutor. Each connection that you build will give you the chance to create more conversations (ibid).

Keeping a conversation going requires certain skills, but once you know what to do, the task is going to be easier.

- Listen to the other persons and figure out what they want to talk about. When you listen to a person's talk, you'll be able to save some ideas or facts that will keep the exchange going.

- Ask questions, but avoid ones with "yes" or "no" answers. A yes/no question is a conversation killer because it allows people to take the easy way out and give only the bare minimum when answering a question.

- Act enthusiastic and interested. Put extra enthusiasm into your questions when asking about another person. It's not so much faking enthusiasm as psyching yourself up when asking a question. It's not exactly hard to do, and it makes the other person feel appreciated.

- Defuse awkwardness by joking about it. Call attention to awkwardness in a joking manner to defuse it. Maybe the conversation died down a bit and silence has taken over. Comment on it in a joking manner. This brings the awkwardness out front and center, making it suddenly something neither of you is afraid of.

Don't be afraid of going deeper. Although it's difficult to do well, many people enjoy bringing their conversation to a deeper level because it's satisfying and makes them happier. If you get the sense that the person you're talking with enjoys more than superficial talk, don't be afraid to go there with a pointed question (www.wikihow.com/Keep-a-Conversation-Going).

Fine (2005, p. 42) introduces four steps to keep an excellent conversation going:

1) Maintain eye contact.

2) Small smile.

3) Find the appropriate person!

4) Introduce yourself, use your name and use theirs.

According to Philpot and Curnick (2011, pp. 30-31), to keep a conversation going, invite the other person to speak by:

- $\quad$ Asking a new question, e.g., Is this the first time you've been here?

- $\quad$ Asking for further, more detailed, information, e.g., Where exactly? What a pity? How awful?

- Returning a question, e.g., And you?/yours? What/How about you? Such a type of question will keep the speaker to keep talking. 
- Showing interest in what the speaker is saying. Use: "Really?", "And?" (With a rising tone), "Right" or "Sure". You might even give an impression that you are listening with a non-word such as "Mmm" or "Uh-huh".

- Repeating a keyword with rising intonation, i.e., repeating what the other person said, e.g.: I am going to London next week. "London!" You can also express stronger interest by increasing the level of your voice.

\section{Hypotheses}

It is hypothesized that:

1) Engaging in a conversation may not be easy for Iraqi EFL learners at a four-year stage.

2) Sustaining spoken communication may not be achieved by those learners at this stage.

\section{Methods}

\subsection{Participants}

The subjects engaged in this study are of 50 Iraqi EFL undergraduate students. The random sample includes learners whose major is the English language. They are fourth-year students at the Department of English, College of Education for Humanities, University of Babylon for the academic year 2017-2018, so they are regarded as advanced candidates. They share the same background, 29 females and 21 males, and their age ranges from 22-25. The subjects already took two courses in "Conversation" during the academic years 2014-2015 and 2016-2017.

\subsection{Instrument}

The test is a method built systematically to gather relevant and reliable information in order to make decisions. It may concentrate on different parts of a course: the achievement of the learners, the teachers, quality of the materials, the appropriateness of the objectives, the teaching methodology, the syllabus etc. (Sárosdy et al., 2006, p. 131). For a test to be good, it stands in need of two basic features, i.e., validity and reliability. Not having these two characteristics the test would be questionable. Validity refers to the degree to which the test actually measures what it is claimed to measure (Richards \& Schmidt, 2010, p. 622). It is of two types: face validity and content validity. The former ascertains that the measure appears to measure the intended construct under study. To ensure the test, it is exposed to jury members to assess its validity. While the latter ensures that the measure actually measures what it is under consideration to measure and not other variables (Perry, 2005, p. 91). From the other hand, Test reliability refers to the degree to which a test gives stable and consistent results when it is given to different people on different events (Richards \& Schmidt, 2010, p. 495). The estimation of the reliability of the test has been carried out using a Kuder-Richards Formula: $\mathrm{R}=\mathrm{N} / \mathrm{N}-1\left[\mathrm{~m}(\mathrm{~N}-\mathrm{m}) / \mathrm{NX}^{2}\right]$, where R typifies reliability, $\mathrm{N}$ typifies how many items in the test, $\mathrm{m}$ typifies the mean scores of the test, and $\mathrm{X}$ typifies the test standard deviation of the scores.

Conforming to what has been mentioned; an indicative test of (20) items is laid out to detect the students' ability in keeping the conversation going. The test consists of an introduction briefed the reader with what is required in it and two parts. Commencing with the first one which takes the form of a recognition test, it consists of (10) items to reveal the subjects' ability to recognize the type of expression showing how a conversation is going when choices are given. The subjects are required to choose the correct choice from a variety of options. The second part of the test which comprises (10) items is intended to elicit information about the students' abilities, at the production level, to issue certain expressions in order to keep a conversation going The test was submitted to a jury of experts from the Department of English/College of Education/University of Al-Qadisiyah to verify its validity (See Appendix 1).

\subsection{Procedure}

The test was printed out and distributed to the participants. One session at the University of Babylon was held to do the test. First, the subjects were orally briefed with the nature of the test and how to respond to its items. Then, they were asked to provide the answers. It took 26-33 minutes to answer the items. For randomization purpose, three versions of the test were prepared which have the same 20 items but with different order. The randomized versions were distributed randomly on the subjects. Finally, the test was piloted with five EFL learners to verify being achieved and gain control of any problems prior to conducting the experiment.

\section{Findings and Discussion}

This portion is assigned to the discussion the results of the test which give a peculiar idea about the learners' expertise in engaging in a conversation. These results are crucial to confirm or disconfirm the hypotheses of the study. 


\subsection{Learners' Performance to the First Question of the Test}

The first question is allotted to testing the learners' achievement at the recognition level. The table below shows the results obtained from each item in the question:

Table 1. Learner's achievement in question (1)

\begin{tabular}{lllllll}
\hline No. of Items & No. of Correct Responses & $\%$ & No. of Incorrect Responses & $\%$ & No. of Avoided Items items & $\%$ \\
\hline 1 & 36 & 72 & 8 & 16 & 6 & 12 \\
2 & 32 & 64 & 11 & 22 & 7 & 14 \\
3 & 31 & 62 & 13 & 26 & 6 & 12 \\
4 & 27 & 54 & 14 & 28 & 9 & 18 \\
5 & 30 & 60 & 13 & 26 & 7 & 14 \\
6 & 37 & 74 & 7 & 14 & 6 & 12 \\
7 & 35 & 70 & 8 & 16 & 7 & 14 \\
8 & 38 & 76 & 6 & 12 & 6 & 12 \\
9 & 27 & 54 & 10 & 20 & 13 & 26 \\
10 & 36 & 72 & 7 & 14 & 7 & 14 \\
Total & 329 & 65.8 & 97 & 19.4 & 74 & 14.8 \\
\hline
\end{tabular}

What stands out in this table is that (65.8) of the first question items have been recognized successfully by the learners, whereas (34.2) of those items (including the ignorant items) have been undistinguished by them. Here, the highest rate of the correct responses is $(76 \%)$ in item (8). The reason may be assigned to the fact that the leaners are well-informed of item (8), while it is (54\%) for items (4) and (9). It is apparent that lacking the skills to answer these items could be a major factor if not only the one which leads to this negative result.

\subsection{Learners' Performance to the Second Question of the Test}

Question two is earmarked for measuring the performance of the learners at the production level. The learners are asked to respond to each item. The learners' responses on each item are displayed in Table 2 below:

Table 2. Learners' Achievement in Question (2)

\begin{tabular}{lllllll}
\hline No. of Items & No. of Correct Responses & $\%$ & No. of Incorrect Responses & $\%$ & No. of Avoided Items items & $\%$ \\
\hline 1 & 33 & 66 & 8 & 16 & 9 & 18 \\
2 & 28 & 56 & 13 & 26 & 9 & 18 \\
3 & 21 & 42 & 14 & 28 & 15 & 30 \\
4 & 18 & 36 & 15 & 30 & 17 & 34 \\
5 & 10 & 20 & 20 & 40 & 20 & 40 \\
6 & 18 & 36 & 10 & 20 & 22 & 44 \\
7 & 16 & 32 & 13 & 26 & 21 & 42 \\
8 & 12 & 24 & 17 & 34 & 21 & 42 \\
9 & 14 & 28 & 9 & 18 & 27 & 54 \\
10 & 8 & 16 & 10 & 20 & 32 & 64 \\
Total & 178 & 35.6 & 129 & 25.8 & 193 & 38.6 \\
\hline
\end{tabular}

What can be easily observed in this table is that (35.6) of the second question items have been perceivable by the learners, whereas (64.4) of those items (including the avoided items) have been barely distinguishable by them. Hence, the highest rate of the correct responses is (66\%) in item (1). The reason may be attributed to the fact that the leaners are knowledgeable about item (1), while it is (16\%) for item (10). This result provides an important insight into the learners' inadequacy of this item.

Hereunder is a table displaying the overall results of the test which embraces both the recognition and production levels: 
Table 3. Learners' overall performance in questions (1) and (2)

\begin{tabular}{lllll}
\hline Level & No. of Correct Responses & $\%$ & No. of Incorrect Responses & $\%$ \\
\hline Recognition & 329 & 65.8 & 171 & 34.2 \\
Production & 178 & 35.6 & 322 & 64.4 \\
Total & 507 & 50.7 & 493 & 49.3 \\
\hline
\end{tabular}

This table is quite revealing the learners' overall realization at both the recognition and production parts. It informs that the highest percentage of the learners' correct responses has come to $(507,50.7 \%)$ which is a high achievement rate than that of their incorrect ones which have got to $(493,49.3 \%)$. In this account, the learners show improvement in this area. Therefore, the hypothesis which says that engaging in a conversation may not be easy for Iraqi EFL learners is refuted.

In terms of error production frequency, the learners' lacking expertise in engaging to a conversation reflects their ineffectiveness in this aspect as the total number of their incorrect responses has come to $(322,64.4 \%)$ which is higher than that of their correct ones which have got to $(178,35.6 \%)$. Such figures confirm that the learners encounter more problems at the production level. Thus, this result provides an affirmation of the second hypothesis which reads that communication may not be achieved by those learners at their fourth stage.

In this investigation, there are several types of errors. The most frequent ones made by the majority of the students can be outlined as follows: incorrect order of sentences, the absence of punctuation marks, wrong choice of acts, failure to answer in grammatical sentences, giving no responses and lack of subject-verb agreement.

\section{Error Types and Causes}

Crystal (2003, p. 165) sees that error analysis is a particular way to identify, classify and methodically interpret the improper responses produced by the learners who learn a foreign language, using any of the procedures and methods provided by linguistics. Furthermore, (Keshavarz, 2012, p. 168) claims that error is "a procedure used by both researchers and teachers which involves collecting samples of learner language, identifying errors, classifying them according to their nature and causes, and evaluating their seriousness".

The analysis of the learners' incorrect responses has reported that their errors can be regarded as resulting from four main types of error source:

1) Errors can be assumable to the negative transfer of the first language's structure into the target language producing the incorrect structure (Odlin, 1989, p. 27), as in item (1), Question (1) the possible answer:

Hi, Lucy! How's your family?

* Hello, Sally.

The impact of the mother tongue invention on the learners' performance leads to lower incomes.

2) Errors can be ascribable to be caused by the transfer of the learner's knowledge of the target language rules to cases in that language where such rules are inapplicable (Ellis, 1994, p. 710), as in item (1), Question (2), the plausible answer:

Really? What did you do?

* Yes? What did you do?

At the recognition level, many of the test items are incorrectly answered due to intralingual overgeneralization. The learners are not aware of when conversation works and when it doesn't. They do not always abide by the rules they learned. Item (8), Question (2): the plausible answer:

Yes, why?

* Yes, it is.

3) Errors can be imputable to some strategies employed to fill the gap of the learner's knowledge in facing the task of communicating meanings such as guessing, approximation, and avoidance (Schmitt, 2002, p. 179), as in many test items which are answered incorrectly at the production level. This outcome can be observed in Question (2) items (6), (9) and (10) where the learners avoid answering them.

4) Errors can be attributable to the negative influence of certain factors of the learning process such as poor learning environments, inadequate learning materials and poor syllabus design (Brown, 1987, p. 179). This may give rise to form misconception of the material, as in items (5), Question (2): the plausible answer: 
Yes, it is. What about you?

* Yes, it is. the first term?

\section{Conclusions}

The most obvious findings to emerge from this study is that: the overall level of the learners' correct responses in the whole test, $(65.8 \%)$, is higher than their level of the incorrect one (34.2\%), and that is a real sign of their skillfulness in engaging a conversation. At the production level, the leaners' incorrect responses in Question (2), $64.4 \%$ ) come out that the learners are unqualified to communicate correctly. The factors behind bring about this rate of the learners' incorrect responses at both performance levels can be attributed to four major types of error source. Firstly, the result of error causes has demonstrated that intralingual overgeneralization plays a vital part in inhibiting the conversation rolling. Correspondingly, it involves improving the learners' ability with more practice on the conversation as they are affected by the rules of the target language. Secondly, the interlingual errors in the learners' responses reveal that the learners are ineligible for the correct production of conversation. Thirdly, as learners encounter communication problems caused by a lack of linguistic resources, they resort to haphazard answers to cope with communication demands. They use different communication strategies to express their intended meaning. The last kind of errors which can hinder learning is known as the context of learning such as, the classroom, the teacher, and the material. They negatively affect the process of learning the target language and as a result, they can create gaps in the learners' knowledge of this language.

\section{Value}

It is reckoned that this study is to be of worthwhile as it sheds light on an important issue in English namely conversation. It is also beneficial to teachers, syllabus designers and learners as they will be aware of how to shape a conversation and how to contribute it.

\section{Acknowledgments}

Thanks and respect to Professor Dr. Abbas Degan Darweesh, Department of English, College of Education for Humanities, the University of Babylon for his valuable remarks and guidance. I also would like to extend my sincere thanks to Professor Dr. Muhammed Jasim Buti, Department of English, College of Education, the University of Thiqar for his useful suggestions in constructing the test. I acknowledge with gratitude to Dr. Sadiya Wudaa Hassan, Department of English, College of Education, the University of Al-Qadisiyah for providing me with all necessary information for completing this project.

\section{References}

Brown, H. D. (1987). Principles of Language Learning and Teaching (2nd ed.). Englewood Cliffs. New Jersey: Prentice -Hall Inc.

Cheng, W. (2003). Intercultural Conversation. Hong Kong: John Benjamins B. V. https://doi.org/10.1075/pbns.118

Conklin, M. G. (2009). What to Say and How to Say It. Portland: The Floating Press.

Cook, G. (1989). Discourse. Oxford: Oxford University Press.

Crystal, D. (2003). A Dictionary of Linguistics and Phonetics (5th ed.). London: Blackwell.

Cutting, J. (2002). Pragmatics and Discourse. London: Routledge.

Ellis, R. (1994). The Study of Second Language Acquisition. Oxford: Oxford University Press.

Fine, D. (2005). The Fine Art of Small Talk: How to Start a Conversation, Keep it Going, Build Networking Skills—and Leave a Positive Impression. New York: Hachette Books.

Gabor, D. (1983). How to Start A Conversation and Make Friends. New York: Simon \& Schuster.

Geis, M. L. (1995). Speech Acts and Conversational Interaction. Cambridge: Cambridge University Press. https://doi.org/10.1017/CBO9780511554452

Hayashi, S. K. (2011). Conversations for Change. New York: McGraw-Hill Companies. Retrieved from https://en.wikipedia.org/wiki/Conversation

Jaffe, J. (2007). Join the Conversation. Hoboken: John Wiley \& Sons, Inc.

Jenlink, P. M., \& Banathy, B. H. (2008). Dialogue as a Collective Means of Design Conversation. New York: Springer Scientific + Business Media, LLC. https://doi.org/10.1007/978-0-387-75843-5 
Keller, E., \& Warner, S. (1990). Conversation Gambits: Real English Conversation Practice. London: Language Teaching Publications.

Keshavarz, M. H. (2012). Contrastive Analysis and Error Analysis (2nd ed.). Tehran: Rahnama Press.

Liddicoat, A. J. (2007). An Introduction to Conversation Analysis. London: Athenaeum Press Ltd.

Odlin, T. (1989). Language Transfer. Cambridge: Cambridge University Press. https://doi.org/10.1017/CBO9781139524537

Perry, Jr. F. L. (2005). Research in Applied Linguistics. New Jersey: Lawrence Erlbaum Associates, Inc.

Philpot, S., \& Curnick, L. (2011). Headway Academic Skills. Oxford: Oxford University Press.

Pridham, F. (2001). The Language of Conversation. London: Routledge.

Radford, A., Atkinson, M., Britain, D., Clahsen, H., \& Spencer, A. (2009). Linguistics: An Introduction. Cambridge: Cambridge University Press. https://doi.org/10.1017/CBO9780511841613

Richards J. C., \& Schmidt, R. (2010). Longman Dictionary of Language Teaching and Applied Linguistics (4th ed.). London: Routledge

Sárosdy, J. et al. (2006). Applied Linguistics 1 for BA Students in English. Humanities Consortium.

Schmitt, N. (2002) An Introduction to Applied Linguistics. London: Arnold.

Turnbull, W. (2003). Language in Action: Psychological Models of Conversation. Hove: Psychology Press. https://doi.org/10.4324/9780203360859

Yule, G. (1996). Pragmatics. Oxford: Oxford University Press.

\section{Appendix 1}

\section{The Test}

Q1/ Underline the expressions showing a conversation going.

1) A Hi, Lucy!

B Hello, Sally. How's your family?

A They're fine, thanks. And yours?

B Yes, well, thanks.

2) A This is a great city for a conference.

B Yes, it is. Is this the first time you've been here?

A No, actually, I know the city quite well. What about you?

B This is the first time...

3) A I'm from Chicago.

B Me, too. Where exactly?

A Hyde Park District, near the university. And you.

B I'm quite close to you. I have an apartment...

4) A I've finished my essay. How about you?

B Another five times.

A Oh fine. Will I wait for you?

B If you don't mind.

5) A OK. I think I'll stop and have a break. What do you suggest?

B Yes, I think I will too.

A Well, are you going for lunch now?

B That would be great.

6) A I'm going to stay with friends in Cape Town.

B Fantastic! And how are you going to travel? 
A By plane to Cape Town, of course.

B By plane! How exciting. And how long...

7) A It's a lovely afternoon. The sky is really white.

B Do you want to go to Stanley Park?

A Wow! How about the bikes?

B Come on! I often go riding there.

8) A I went shopping yesterday.

B Really! Where did you go?

A Oxford Street.

B Oh! What did you buy?

9) A I'm looking for a job where I can live.

B What did you want?

A I wouldn't mind working in an office.

B Have you done anything like that before?

10) A The place has got ghosts, apparently.

B Don't be silly. Do you believe in ghosts?

A Why not?

B You're a rational human being. You can't believe all that stuff.

Q2/ Complete these extracts with word(s) or phrases that keep a conversation going:

1) A I had an interesting time this weekend.

B -------------? What did you do?

2) A I went on a study trip to Leyburn.

B ----------------?

3) A Yes, it's a small coastal town in the north.

B Oh, -----------?

4) A Well, it was fascinating. We did a survey of study habits.

B ----------------?

A Yes, study habits. It was amazing what we discovered about...

5) A Is this your first term?

B Yes, it is.

6) A Yes! And I'm having problems finding my lecture room!

B What------------------is that?

7) A Science.

B ---------------?

8) A Yes, -----------?

B I'm studying science, too.

9) A I'm going to do combined chemistry and physics. $-?$

B It's absolutely wonderful.

10) A -------------?

B Oh, sure. Nobody denies the science's favor. 


\section{Appendix 2}

\section{The Test's Possible Answers}

Q1/

1) A Hi, Lucy!

B Hello, Sally. How's your family?

A They're fine, thanks. And yours?

B Yes, well, thanks.

2) A This is a great city for a conference.

B Yes, it is. Is this the first time you've been here?

A No, actually, I know the city quite well. What about you?

B This is the first time...

3) A I'm from Chicago.

B Me, too. Where exactly?

A Hyde Park district, near the university. And you.

B I'm quite close to you. I have an apartment...

4) A I've finished my essay. How about you?

B Another five times.

A Oh fine. Will I wait for you?

B If you don't mind.

5) A OK. I think I'll stop and have a break. What do you suggest?

B Yes, I think I will too.

A Well, are you going for lunch now?

B That would be great.

6) A I'm going to stay with friends in Cape Town.

B Fantastic! And how are you going to travel?

A By plane to Cape Town, of course.

B By plane! How exciting. And how long...

7) A It's a lovely afternoon. The sky is really white.

B Do you want to go to Stanley Park?

A Wow! How about the bikes?

B Come on! I often go riding there.

8) A I went shopping yesterday.

B Really! Where did you go?

A Oxford Street.

B $\underline{\mathrm{Oh}}$ ! What did you buy?

9) A I'm looking for a job where I can live.

B What did you want?

A I wouldn't mind working in an office.

B Have you done anything like that before?

10) A The place has got ghosts, apparently.

B Don't be silly. Do you believe in ghosts?

A Why not? 
B You're a rational human being. You can't believe all that stuff.

Q2 1

1) Really?

2) Leyburn?

3) and...?

4) Study habits?

5) What about you?

6) lecture

7) Really?

8) why?

9) What do you think of that?

10) Do you agree that science does us great favor?

\section{Copyrights}

Copyright for this article is retained by the author, with first publication rights granted to the journal.

This is an open-access article distributed under the terms and conditions of the Creative Commons Attribution license (http://creativecommons.org/licenses/by/4.0/). 